\title{
A Síndrome do Impostor e sua relação com a docência: um estudo com as professoras de ciências contábeis e administração
}

Mariana Azevedo Alves

E-mail: a.marianaazevedo@gmail.com Universidade Federal Fluminense, Volta Redonda, Rio de Janeiro, Brasil

\section{Eduardo Cotrim Ferreira}

E-mail:

eduardo@cotrimcontabilidade.com.br Universidade Federal Fluminense, Volta Redonda, Rio de Janeiro, Brasil

Mariana Pereira Bonfim

E-mail: marianapbonfim@gmail.com Universidade Federal Fluminense, Volta Redonda, Rio de Janeiro, Brasil

\section{RESUMO}

Este trabalho teve como objetivo verificar se as professoras de Ciências Contábeis Administração da Universidade Federal Fluminense são acometidas pela Síndrome do Impostor, além de analisar qual é a relação entre a presença da síndrome e o seu nível de sucesso. Para obter os resultados, 8 professoras responderam o questionário, denominado escala CIPS. Após a análise dos dados, chegou-se à conclusão de que a maior parte das professoras apresentava nível baixo e moderado do indicativo de Síndrome, contrariando a literatura internacional, que apontava no sentido de que mulheres, teoricamente de sucesso, estariam mais propensas a desenvolver a Síndrome em ambientes majoritariamente masculinos. Desta maneira, concluiu-se que o resultado encontrado pode ser fruto das mudanças ocorridas ao longo do tempo, uma vez que há uma distância temporal muito grande entre os estudos pioneiros e o presente artigo.

PALAVRAS-CHAVE: Gênero. Mulher. Mercado de trabalho. Escolhas profissionais. 


\section{INTRODUÇÃO}

A cada dia a representatividade feminina no mercado de trabalho vem aumentando. Todavia, ainda são presentes inúmeros fatores de dificuldades responsáveis pela sobrecarga de trabalho da mulher, dentre os quais é possível citar a conciliação entre a vida profissional e doméstica, esta segunda historicamente delegada ao papel feminino.

Durante décadas, as diferenças de gênero entre homem e mulher foram utilizadas como insumo para a distinção social entre eles. Atualmente, essas mesmas diferenças justificam a necessidade de incorporação da perspectiva de gênero nas análises acerca do papel feminino no contexto em que está inserido, e sua participação em detrimento à do homem no objeto estudado (CRENSHAW,2002).

No Brasil, a presença feminina em atividades econômicas deu-se, principalmente, na década de 1970, acompanhando a expansão da economia que ocorria no país, conjuntamente com o movimento veloz de urbanização e industrialização. Segundo Cristina Bruschini e María Rosa Lombardi (1996) muitas foram as mudanças do perfil das mulheres trabalhadoras desde a época citada.

Além da necessidade econômica, a crescente inserção feminina no mercado de trabalho também se deu por fatores como transformações na cultura e na sociedade que vêm ocorrendo dentro das famílias brasileiras.

Na década de 1970, o perfil mais comum nas atividades econômicas eram mulheres jovens, com baixo nível de escolaridade e solteiras. Na década seguinte, de 1980, este perfil sofreu mudanças: as trabalhadoras eram, em maioria, mulheres com idade acima de 25 anos, mais instruídas, casadas, e com nível maior de renda (BRUSCHINI; LOMBARDI, 1996).

Simone Wajnman e Eduardo Rios-Neto (2000) afirmam que essas mudanças no perfil entre as duas décadas podem ser explicadas pelo fato de que as mulheres começaram a trabalhar em virtude da remuneração que receberiam com o intuito de auxiliar no financiamento das atividades do lar, uma vez que estavam casadas; e também passaram a optar pela permanência em seus empregos, ainda que mudassem o próprio estado civil.

A maior participação feminina no mercado de trabalho também pode ser entendida a partir da perspectiva de Nelio Oliveira, Rita de Cássia Oliveira e Simone Dalfior (2000), que diz que, em sua dinâmica, o mercado exige cada vez mais atributos que são culturalmente considerados femininos, como capacidade de empatia, traquejo no trato com clientes, a criatividade e a flexibilidade.

Eugenia Trancoso Leone (2003) pontua que os espaços na economia tradicionalmente ocupados por mulheres continuaram se reproduzindo ao longo da história, o que gerou nichos ocupacionais, a exemplo do serviço doméstico. Todavia, homens também começaram a ocupar espaços anteriormente ocupados por mulheres, o que implicou na redução de segmentação de gênero. Neste caso, porém, a mesma não ocorreu senão pela redução de oferta no mercado para homens, levando-os à execução de outras atividades.

Em diversos segmentos profissionais é possível e preciso analisar o que representa a ocupação feminina e qual sua configuração dentro do âmbito das relações de trabalho. Assim, esta realidade também pode ser verificada na área 
contábil: a crescente presença de mulheres nos bancos de universidade e, consequentemente, no mercado de trabalho, reforça a necessidade do estudo acerca da sua participação produtiva e social na área.

Segundo o Portal do Conselho Federal de Contabilidade (CFC, 2017), em outubro de 2017 , cerca de $43 \%$ do total geral de profissionais de contabilidade ativos eram mulheres. $\mathrm{O}$ baixo quantitativo de pesquisas sobre a qualidade e as condições desta participação, principalmente atualizadas, justificam a realização deste estudo, uma vez que se trata de uma contribuição para o mapeamento da presença feminina no ramo.

Esta pesquisa embasa-se, principalmente, no estudo realizado por Patrícia Matos (2014), no qual a autora buscou verificar a relação entre a Síndrome do Impostor, a auto eficácia e o desempenho acadêmico de estudantes minoritários nos cursos de Ciências Contábeis e Administração.

O conceito de Síndrome do Impostor foi desenvolvido a partir do estudo de Pauline Clance e Suzanne Imes (1978), no qual mulheres que ocupavam espaços de sucesso profissional e acadêmico foram estudadas e, a partir da análise de resultados, as autoras perceberam que a amostra estudada apresentava, em sua maioria, o sentimento de que estavam enganando aos outros com relação ao seu nível de inteligência e consideravam-se impostoras em suas realizações, seja por acreditarem que seu sucesso deveu-se ao fato de encontrarem-se em um momento oportuno em determinada situação, seja pelo excesso de esforço de sua parte para alcançar a posição ocupada, em detrimento de sua própria competência e habilidade.

Assim, as autoras verificaram que essas pessoas, acometidas pela síndrome, duvidam da própria capacidade intelectual, relegando suas conquistas às mais diversas justificativas que não sua inteligência (CLANCE; IMES, 1978).

Diante do exposto, o presente estudo apresenta o seguinte o problema de pesquisa: A Síndrome do Impostor afeta as professoras de Ciências Contábeis e Administração da Universidade Federal Fluminense?

Este teve como objetivo verificar se as professoras de Ciências Contábeis e Administração da Universidade Federal Fluminense (UFF) da cidade de Volta Redonda/RJ são acometidas pela Síndrome do Impostor, além de analisar qual é a relação entre a presença da síndrome e o seu nível de sucesso. Assim, este artigo pretende verificar se essas professoras que, em tese, atingiram um determinado nível de sucesso, acreditam que estão ali por serem capazes, ou porque algum fator externo ou sua dedicação demasiada as levaram até o patamar em que se encontram no presente momento.

\section{REFERENCIAL TEÓRICO}

Mulheres vivem sob o jugo do preconceito e da segregação desde muito tempo. Na sociedade ocidental, as práticas discriminatórias de gênero foram, por muitas décadas, consideradas aceitáveis e, em muitos casos, aconselháveis. Como exemplo disso é possível citar o caso das Ordenações Filipinas, ordenamento jurídico vigente em Portugal desde 1603 e, da mesma maneira, no Brasil Colonial, consideradas o primeiro modelo de legislação vigente do país, permanecendo em vigor até 1916. Nestas, havia previsão de que era o homem autorizado a aplicar 
castigo físico em sua esposa como medida corretiva e, caso a mesma fosse adúltera, era também facultado a ele o direito de tirar-Ihe a vida (TAVARES,2012).

Um passo decisivo e legitimador dos esforços no sentido de igualdade de gênero no país foi a promulgação da Constituição Federal de 1988, na qual diversos princípios de proteção à mulher foram contemplados, como o inciso I do artigo $5^{\circ}$ :

Art.5‥Todos são iguais perante a lei, sem distinção de qualquer natureza, garantindo- se aos brasileiros e aos estrangeiros residentes no País a inviolabilidade do direito à vida, à liberdade, à igualdade, à segurança e à propriedade, nos termos seguintes: I - homens e mulheres são iguais em direitos e obrigações, nos termos desta Constituição.

No mercado de trabalho, a entrada feminina se deu, principalmente, durante a I Guerra Mundial: incumbidas da tarefa de substituir os homens nas linhas de produção, uma vez que estavam eles lutando em nome de seus países no front, mulheres passaram a exercer atividades fora do lar e serem remunerados por isso. No entanto, ainda que um avanço, a presença dessas mulheres no trabalho fora do lar não as destituiu de suas obrigações domésticas. Por este motivo, foi neste momento que se iniciou a histórica acumulação de tarefas feminina.

Com o fim da II Guerra Mundial e o retorno dos homens às atividades cotidianas e postos de trabalho, esperava-se que a mulher retornasse para dentro de seu lar e de suas tarefas exclusivamente domésticas. No entanto, essa expectativa acabou por se revelar um problema, uma vez que elas seguiram desejando seus trabalhos, o que suscitou o início das reinvindicações feministas em prol de espaço no mercado de trabalho e de igualdade de condições dentro deste (BONIATTI et al., 2014).

No Brasil, a participação feminina no mercado de trabalho deu-se, de forma intensa, a partir da década de 1970, como fruto das movimentações feministas que começaram a se fortalecer no país. Tais movimentações abriram espaços sociais e econômicos para a inserção das mulheres, face às dificuldades econômicas enfrentadas nacionalmente e à crescente automação da indústria, que demandava mão de obra para a operação das máquinas (CAMPELLO; DONATTI, 2015).

Cristina Bruschini e Andrea Puppin (2004) afirmam que um dos motivos que mais influenciaram a entrada da mulher brasileira no mercado de trabalho foi a expansão da escolaridade: com a entrada nas universidades, as mulheres passaram a ocupar cargos que exigiam qualificação específica e passaram a integrar mais robustamente a parcela de pessoas ativas economicamente na sociedade do país.

Segundo Eva Blay e Rosana Conceição (2013), a entrada das mulheres no ensino superior no país ocorreu no final do século XIX, com o ingresso de uma mulher no curso de Medicina, no estado da Bahia, no ano de 1887.

O censo de 2016, divulgado pelo Instituto Nacional de Estudos e Pesquisas Educacionais Anísio Teixeira (INEP), ratifica a presença massiva de mulheres na graduação. Segundo os dados disponibilizados, 3.641 .371 das matrículas ingressantes em Instituições Superiores de Ensino são de pessoas do gênero feminino, enquanto do gênero masculino foram contabilizadas 2.913.020 matrículas.

$\mathrm{Na}$ área contábil, segundo o Conselho Federal de Contabilidade (CFC), a regulamentação da profissão ocorreu no ano de 1946 e no ano de 1991 foi 
realizado o I Encontro Nacional da Mulher Contabilista, com o objetivo de aprimorar os conhecimentos técnicos e culturais através do incentivo à participação das contadoras na vida social e política do país. Atualmente, 42,9\% dos profissionais ativos em contabilidade, segundo o CFC (2017), são mulheres.

Um acontecimento importante no meio contábil foi a ocupação do cargo de presidente do Conselho Regional de Contabilidade do Estado do Rio de Janeiro (CRCRJ) por Diva Maria de Oliveira Gesualdi, uma mulher e a primeira neste posto, entre os anos de 2010 e 2013; tendo sido esta, inclusive, sucedida por outra mulher, Vitória Maria da Silva.

De acordo com Claudia Cavalieri e Reynaldo Fernandes (1998), em Economia há um consenso de que indivíduos com igual capacidade produtiva são avaliados pelo mercado de trabalho por características que não se limitam apenas a atributos como competências e habilidades, como também por características não produtivas tais quais gênero e raça.

Mesmo com sua inserção gradativa em espaços historicamente reservados aos homens, as mulheres ainda sofrem reflexos do machismo arraigado nos meios sociais desde cedo, seja de maneira visível e facilmente identificável, seja de forma sutil e quase imperceptível. Neste sentido, é possível citar a violência simbólica no campo do poder, termo apresentado por Pierre Bourdieu (1989, p. 10), que diz que o poder simbólico é o poder invisível através do qual a cultura, que é imbuída de poder dominante, contribui para a ratificação de sua dominação e a desmobilização daqueles que são dominados, os quais não conseguem perceber a violência aguda a qual estão expostos no cotidiano, tampouco apresentar reações a ela.

Então, ainda conforme o autor, a cultura que une os que estão em condição predominantes, é também a responsável por separar e legitimar as diferenciações de estruturas de domínio (BOURDIEU, 1989). Assim, quando há, por exemplo, a exigência de características masculinas para determinado cargo, atribuídas também por homens (dominantes), e justificadas justamente por este motivo, afirma-se que mulheres (dominadas) não podem exercer tal atividade, havendo a concretização da violência simbólica.

Segundo Bourdieu (2002, p. 75), a violência simbólica "contribui para construir a situação diminuída das mulheres e cujos efeitos cumulativos estão registrados nas estatísticas da diminuta representação das mulheres nas posições de poder, sobretudo econômico e político".

Essa experiência, de ser alvo de episódios fundamentados sob a lógica machista, produz reflexos profundos, os quais necessitam serem avaliados e estudados de forma meticulosa para que seja possível entender de que maneira se dão e quais as consequências práticas e implícitas geradas por estas ocorrências.

É possível supor, como um desses desdobramentos, o fenômeno conhecido como Síndrome do Impostor na perspectiva de gênero. Segundo Matos (2014), aqueles que são acometidos dessa Síndrome, também denominados impostores, subestimam a própria inteligência, acreditando que têm suas capacidades superavaliadas por outras pessoas, e atribuem suas realizações à sorte ou ao excesso de esforço, ainda que seja possível inferir com certeza suas habilidades e competências. 
As primeiras a falarem sobre a Síndrome do Impostor na literatura foram Clance e Imes (1978) ao verificarem em seus estudos uma quantidade enorme de mulheres que alegaram se considerarem impostoras, ainda que tivessem sucesso acadêmico e profissional; além de terem medo de serem descobertas enquanto a farsa que acreditavam ser.

Jane Roskowski (2010) indica que a Síndrome, embora abarque aspectos como a ansiedade e a baixa autoestima, diferencia-se dos estados citados por possuir outro componente: o sentimento de fraude.

Cabe dizer que, pelo fato de o início das pesquisas da Síndrome terem sido feitas em mulheres, inicialmente houve a suposta formulação da ideia de que a síndrome acometia apenas pessoas do gênero feminino. Contudo, diversos estudos demonstram que o fenômeno não ocorre apenas em mulheres. A pesquisa de Joan Harvey (1981), por exemplo, realizada com alunos/as do ensino superior, demonstrou que houve maior ocorrência da mesma entre os/as melhores alunos/as, independente de qual gênero eles pertenciam.

Corroborando com essa ideia, Roskowski (2010), também verificou, em seus estudos, a ocorrência da síndrome em ambientes corporativos e de graduação nos quais a maioria era do sexo feminino e a minoria do sexo masculino, notando-se assim a ocorrência também em homens.

Assim, esse estudo foi aplicado em mulheres por serem elas minorias dentro dos departamentos em que estão inseridas, o que as tornam, à luz da teoria, mais propensas a serem afetadas pelo fenômeno da Síndrome.

Com relação às características das pessoas que sofrem da Síndrome, em suas análises, Clance (1985) notou que um comportamento recorrente dos/as impostores/as era a tendência de se lembrarem rapidamente de algum feedback negativo, bem como a propensão a negar ou se esquecer sobre os feedbacks positivos que tenham recebido. Assim, ainda que os recebessem, não relatavam quando perguntados/as a respeito.

Em ambientes de convívio social, o/a impostor/a tende a formular justificativas para seu bom desempenho, a fim de estar protegido/a do medo e do fracasso. Nesse sentido, aquele que sofre/a com a Síndrome subjuga suas próprias habilidades e diminui suas próprias conquistas (COWMAN; FERRARI, 2002).

Shaun Cowmann e Joseph Ferrari (2002) demonstram em suas pesquisas que os/as impostores/as têm tendências a serem workaholic. Isso ocorre uma vez que, vislumbrando o possível fracasso, estes/as tendem a dedicarem-se excessivamente à tarefa dada como incumbência, a fim de chegar a resultados minimamente satisfatórios e não serem descobertos/as.

Além disso, pessoas que portam a síndrome tendem à auto sabotagem, a nunca terminar tarefas começadas, fazer uso do carisma para obter aprovação e a procrastinação (CLANCE; IMES, 1978).

Outra característica recorrente está relacionada ao trabalho e estudo excessivo, como meio de acobertar a "verdade" sobre sua falta de competência e habilidade. Movida por este temor, a mulher empenha-se arduamente, o que a leva a alcançar excelentes resultados. Dentro deste ciclo, ela fica eufórica com o próprio êxito, mas a euforia é rapidamente arrefecida, dando início novamente ao ciclo da síndrome. 
A relevância do estudo da Síndrome do Impostor advém do fato de que pessoas que não se reconhecem como impostores/as não conseguem chegar aos resultados almejados, o que pode levá-los/las, inclusive, a esquivarem-se de possibilidades que oportunamente possam aparecer para progredirem. Nesse sentido, pesquisas demonstram que as pessoas que sofrem da síndrome tiveram interferências em suas carreiras pela manifestação da mesma (CLANCE; O'TOOLE, 1988).

Não existem conclusões acerca do momento exato do surgimento da Síndrome do Impostor, mas Clance e Imes (1978) sugerem que o fenômeno se desenvolve no seio familiar. Seu estudo apresentou duas sugestões para a origem da síndrome dentro da amostra estudada (lembrando que este estudo tinha como foco, as mulheres): a primeira hipótese é de que mulheres que tinham algum familiar próximo considerado como a pessoa "inteligente" do seio parental, eram taxadas de "sensíveis" e usavam do seu desempenho escolar como meio de provar sua inteligência. Em episódios de insucesso, essas mulheres começavam a questionar a própria capacidade intelectual e a associar seu bom desempenho a atributos como sua simpatia e maleabilidade com as pessoas, e não à sua inteligência.

A segunda hipótese é a de que mulheres que foram incentivadas desde cedo por sua família em diversos aspectos - intelectual, de talento, de aparência e de personalidade -, questionam o posicionamento de seus pais ao verificar que precisam se esforçar nos estudos para garantir o bom desempenho; o que contraria sua percepção anterior de que conseguiria com facilidade atingir às metas previamente estabelecidas, levando-as a crer que não são tão inteligentes quanto foram induzidas a acreditar.

Dessa forma, esse estudo pretende verificar se as professoras do departamento de Ciências Contábeis e Administração da UFF (Volta Redonda) são acometidas pela Síndrome do Impostor, uma vez que elas atingiram cargos de sucesso em suas profissões, sendo as mesmas ocupadas, majoritariamente, por homens.

\section{METODOLOGIA}

A pesquisa desenvolvida para este artigo é de natureza básica e toma como abordagem a pesquisa qualitativa, uma vez que valoriza o sujeito na análise do problema proposto, a fim de perceber qual é o comportamento dos/as atores/atrizes do processo dentro do contexto em que está inserido/a.

De acordo com Maria Cecília Minayo (2001) a pesquisa qualitativa enveredase pelo caminho da subjetividade uma vez que certas variáveis e quantificações não são capazes de exprimir a complexidade das relações, as quais são profundas, e dotadas de significados, valores, crenças e motivações.

O objetivo desse estudo é o de ser uma pesquisa descritiva, uma vez que busca expor detalhes acerca da ocorrência ou não da Síndrome anteriormente exposta no grupo escolhido para estudo. Segundo Gil (2008), a pesquisa descritiva propõe-se ao estudo detalhado da incidência dos fenômenos de um determinado objeto ou realidade de onde parte o/a pesquisador/a no início do seu estudo, com o objetivo de descrever os atributos de determinadas populações ou fenômenos. 
No que tange aos procedimentos, esse estudo se trata de uma pesquisa com survey, uma vez que as informações acerca dos dados que se pretende conseguir foram extraídas diretamente do grupo de interesse. A pesquisa survey vale-se do questionário como ferramenta para a obtenção de informações acerca das características e opiniões de um agrupamento específico de pessoas (FONSECA, 2002).

Este trabalho utilizou o questionário elaborado por Clance (1985), denominado escala CIPS - Clance Impostor Phenomenom Scale - a qual foi desenvolvida para a detecção de características impostoras possíveis de serem observadas clinicamente (HOMES et al., 1993). O intuito do uso desta escala é fazer a verificação da ocorrência ou não dos indicadores da Síndrome do Impostor nas mulheres estudadas.

O questionário é composto por 20 questões que visam identificam os tópicos listados a seguir:

- Medo de Avaliação

- Medo de Não ser capaz de repetir o sucesso

- Medo de ser menos capaz do que os/as outros/as

Segundo Clance (1985), os itens são classificados em escala Likert, de cinco pontos, onde há a variação entre 1 (não é de todo verdade) e 5 (muito verdadeiro), e o resultado é tomado como indicativo da presença ou não de sintomas da Síndrome do Impostor, conforme Quadro 1, a seguir:

Quadro 1 - Escala da pontuação das respostas

\begin{tabular}{|c|c|}
\hline Pontuação & Indicativo \\
\hline Acima de 80 & Elevado nível da síndrome \\
\hline Entre 61 e 80 & Nível alto da síndrome \\
\hline Entre 41 e 60 & Níveis moderados da síndrome \\
\hline Abaixo de 40 & Baixos níveis da síndrome \\
\hline
\end{tabular}

Fonte: Elaborada pelos autores com base em Clance (1985).

A escala utilizada nesta pesquisa é a tradução aplicada por Matos (2014) do questionário original, em inglês. O recorte do gênero feminino foi escolhido para a realização do estudo por ser um segmento de minorias sociais, embora Holmes et al. (1993) demonstre que homens e mulheres são semelhantemente acometidos pela Síndrome. Além do questionário, a única informação exigida era com relação ao curso no qual as docentes estavam vinculadas, uma vez que, dada a amostra pequena, solicitar outras informações poderia implicar na identificação da respondente, o que poderia inibir as mulheres de responderem.

Foi realizado um pré-teste para verificar a eficácia e clareza do formulário. Foram enviados a 13 mulheres profissionais da área contábil dois modelos do questionário, ambos compostos pelas 20 perguntas originais, tendo um modelo 5 opções de resposta sendo elas: 1) Não é de todo verdade; 2) Raramente; 3) Às vezes; 4) Frequentemente; 5) Muito verdadeiro.

O segundo modelo foi composto de apenas 3 alternativas: 1) Não é de todo um número igual de mulheres e verificou-se que os dois seriam suficientes para a 
obtenção dos resultados necessários para a análise a que se propõe no presente trabalho. Dessa maneira, optou-se pela utilização do questionário com 5 alternativas, mantendo-se fiel ao originalmente proposto por Clance (1985).

O questionário foi enviado via formulário online, por questões de conveniência, a professoras do curso de Ciências Contábeis e Administração da Universidade Federal Fluminense (UFF) do campus de Volta Redonda, a um total de 9 professoras. O foco dessa pesquisa está voltado para o curso de Ciências Contábeis, contudo, o questionário também foi aplicado às professoras de Administração, pois elas lecionam disciplinas no curso de Contabilidade, tais como Administração Financeira e Orçamentária e Métodos Quantitativos, por exemplo. O primeiro envio dos questionários foi feito no dia 26 de março de 2018 e, para aquelas que não responderam, foi feito reenvio no dia 10 de abril de 2018. Além disso, 2 professoras preferiram respondê-lo manualmente. Dos formulários enviados, 8 foram respondidos e embasaram a presente pesquisa, não tendo, a nona professora, respondido por já estar aposentada quando do recebimento do questionário.

\section{ANÁLISE DOS RESULTADOS}

As respostas foram obtidas de forma eletrônica e manual e, então, os dados foram compilados no software Excel ${ }^{\circledR}$, para serem analisados. Após a realização da contagem dos resultados obtidos, chegou-se aos seguintes níveis de Síndrome do Impostor na amostra pesquisada:

Quadro 2 - Níveis da síndrome de impostor na amostra

\begin{tabular}{|c|c|}
\hline Indicativo de Síndrome do Impostor & Quantidade de pessoas \\
\hline Nível Baixo & 4 \\
\hline Nível Moderado & 3 \\
\hline Nível Alto & - \\
\hline \multicolumn{2}{|c|}{ Nível Elevado } \\
\hline \multicolumn{2}{|c|}{ Fonte: Dados da pesquisa (2018) - elaboração própria. }
\end{tabular}

Das professoras respondentes, 5 eram do curso de Ciências Contábeis e 3 do curso de Administração. Notou-se que das professoras de Ciências Contábeis, uma estava no nível elevado, 2 no nível moderado e, mesmo as 2 que estavam com nível baixo, chegaram próximas ao nível moderado, totalizando 39 pontos ambas. É válido lembrar que a partir de 41 pontos, o respondente já deve ser considerado como pertencente ao índice moderado. Com relação às professoras de Administração, uma estava em nível moderado e duas em nível baixo, com 26 e 25 pontos, estando, então, distantes do nível Moderado.

Assim, considerando os resultados expostos e somente com relação à amostra pesquisada, é possível verificar que, das professoras de Ciências Contábeis analisadas, as mesmas apresentaram um grau maior de indicativo de síndrome, se comparadas às professoras de Administração avaliadas.

Com relação à professora com elevado índice da síndrome, 15 das 20 frases foram assinaladas por ela como "muito verdadeiro" e nenhuma das frases foi marcada como "não é de todo verdade", demonstrando a real identificação desta com as frases do formulário em algum grau, que não o mínimo possível, 
representado pelo número 1 . É válido dizer que ela fez 90 pontos de um total de 100.

Além das questões que foram respondidas com o número 5 pela professora com elevado índice, apenas duas questões tiveram outra professora que também se identificou de forma "muito verdadeira", alternativa indicada pelo número 5 . Foram elas:

a) "Às vezes, penso que eu obtive minha posição de sucesso atual porque aconteceu de eu estar no local certo na hora certa e/ou por conhecer as pessoas certas";

b) "Se eu não sou o "melhor" em situações que envolvem conquista, eu me sinto mal e desanimado".

Foi feita uma estatística descritiva dos dados, que apresentou os seguintes resultados:

Tabela 1 - Estatística descritiva dos dados

\begin{tabular}{|c|c|c|c|c|c|}
\hline Questões & Média & Moda & Desvio Padrão & Mínimo & Máximo \\
\hline Q1 & 1,75 & 2 & 0,707107 & 1 & 3 \\
\hline Q2 & 2,125 & 2 & 1,356203 & 1 & 5 \\
\hline Q3 & 2,875 & 2 & 1,356203 & 1 & 5 \\
\hline Q4 & 2,5 & 2 & 1,414214 & 1 & 5 \\
\hline Q5 & 2,625 & 1 & 1,685018 & 1 & 5 \\
\hline Q6 & 2,5 & 2 & 1,414214 & 1 & 5 \\
\hline Q7 & 2,625 & 2 & 1,407886 & 1 & 5 \\
\hline Q8 & 2,75 & 4 & 1,164965 & 1 & 4 \\
\hline Q10 & 1,75 & 1 & 1,38873 & 1 & 5 \\
\hline Q11 & 2,125 & 2 & 1,356203 & 1 & 5 \\
\hline Q12 & 1,875 & 1 & 1,457738 & 1 & 5 \\
\hline Q13 & 2,375 & 2 & 1,187735 & 1 & 4 \\
\hline Q14 & 2 & 1 & 1,414214 & 1 & 5 \\
\hline Q15 & 2,375 & 2 & 1,30247 & 1 & 5 \\
\hline Q16 & 1,5 & 1 & 0,755929 & 1 & 3 \\
\hline Q17 & 2,5 & 2 & 1,414214 & 1 & 5 \\
\hline Q18 & 2,625 & 2 & 1,30247 & 1 & 5 \\
\hline Q19 & 3,25 & 3 & 1,035098 & 2 & 5 \\
\hline Q20 & 2,25 & 1 & 1,752549 & 1 & 5 \\
\hline & 0196 & & 1 & 1 & \\
\hline
\end{tabular}

Fonte: Dados da pesquisa (2018) - elaboração própria.

Analisando os dados é possível inferir que a moda, de maneira geral, está entre 1 e 2 para as assertivas apresentadas no questionário (vide apêndice), e a média varia, em maioria, entre 2 e 2,5. Este indicativo corrobora com o resultado geral de baixo índice de Síndrome do Impostor. No entanto, pode-se notar dois resultados destoantes no que tange à moda.

Na questão 8, a moda foi de 4, indicando alta identificação das respondentes com a alternativa, que dizia que "Raramente eu desenvolvo uma tarefa tão bem quanto eu gostaria de fazê-la". Pode-se supor que essa identificação ocorra uma vez que as professoras acreditem ou realmente não possuam o tempo necessário para realizar as tarefas a que se propõem com a acurácia que acreditam ser devida para o desenvolvimento desta. 
Além da questão 8 , outra questão que teve moda diferenciada foi a questão 19, com moda 3. Essa questão dizia que "Se eu receber uma promoção ou reconhecimento de algum tipo, hesito em contar aos outros até que o fato seja consumado". A partir deste resultado, é possível pensar que talvez por considerarem que seus êxitos são frutos de um equívoco ou acaso, ou por não se sentirem suficientemente seguras acerca de sua própria competência para atrelálas ao resultado (no caso, a promoção) a si mesma, essas professoras tendem a não compartilhar o reconhecimento do próprio trabalho até que realmente tenham certeza de que este ocorrerá, para se precaverem do desconforto de admitirem que não mais o terão, caso não haja a concretização do fato.

Também é possível perceber, a partir da análise dos dados, que há uma amplitude alta entre o máximo e o mínimo apresentado em cada questão. Em quase todas as questões o mínimo assinalado foi 1, e o máximo, 5.

Além do resultado apresentado, duas das professoras respondentes alegaram sentir falta da resposta "não", e disseram que acreditam que "não é de todo verdadeiro" não é suficiente para expressar uma resposta absoluta.

Assim, é possível verificar, então, que a maior parcela das respondentes apresentara grau baixo e moderado da Síndrome. Percentualmente, os indicativos seguiram a distribuição indicada na tabela a seguir:

Quadro 3 - Percentual das respostas

\begin{tabular}{|c|c|}
\hline Indicativo de Síndrome do Impostor & Quantidade de pessoas (\%) \\
\hline Nível Baixo e Moderado & $87,5 \%$ \\
\hline Nível Alto e Elevado & $12,5 \%$ \\
\hline
\end{tabular}

Fonte: Dados da pesquisa (2018) - elaboração própria.

Esses dados refutam o resultado de outras pesquisas internacionais, uma vez que segue no sentido oposto da ideia de que, quanto maior o nível de sucesso, maior a propensão de portar a Síndrome.

No entanto, o trabalho no qual se fundamenta o presente artigo, Matos (2014) também encontra resultado contrário com relação à ocorrência da Síndrome, do que foi evidenciado no estudo de Clance e Imes (1978). Em seu trabalho, no qual a autora aplica a mesma escala CIPS para 492 alunos minoritários (beneficiados por programas sociais para acesso ao ensino superior privado) dos cursos de Ciências Contábeis e Administração, também foi encontrado maior número de respondentes encaixados em nível baixo e moderado $(78,8618 \%)$, em comparação com aqueles enquadrados no nível alto e elevado $(21,1382 \%)$.

Como é possível notar, os resultados encontrados por este trabalho são extremamente próximos dos resultados encontrados por Matos (2014), o que pode indicar uma nova configuração no perfil daqueles que sofrem da Síndrome, que não mais sejam as minorias nos espaços em que estão inseridas.

Além do exposto, o resultado encontrado neste trabalho já havia sido verificado também no pré-teste aplicado, no qual a maior parte das respondentes também apontou a existência de nível baixo e moderado de indicativo, em sua maioria.

Algumas suposições podem tentar justificar os números descobertos: a primeira é que há uma distância temporal muito grande entre os estudos pioneiros 
sobre a Síndrome, realizados na década de 70, e a atualidade. Com as mudanças que a sociedade vem passando no sentido de maior emancipação feminina, representatividade em espaços anteriormente considerados masculinos e ocupação cada vez maior de postos de sucesso, pode ser que a Síndrome não seja mais tão recorrente quanto na época onde ainda se iniciava o deslocamento da ótica machista sobre qual era o papel da mulher em meios sociais e a tomada de poder destas.

Outra hipótese que auxilia na compreensão diz respeito ao campus estudado: o campus Aterrado, onde foi realizada a pesquisa, situa-se na cidade de Volta Redonda, interior do estado do Rio de Janeiro, não sendo o campus central da UFF nem o principal da Universidade na cidade. Além disso, ambos os departamentos, de Administração e Contabilidade, contam com 22 e 15 professores, respectivamente. Nesse sentido, é possível também que as professoras da Universidade não tenham total noção a respeito do espaço que ocupam: ser professora de uma Universidade Federal é, consensualmente, um espaço de sucesso. No entanto, pode ser que, dada a pequena dimensão do campus em questão, as professoras não se enxerguem como pessoas de sucesso que socialmente se presume ser por conta de seu status profissional, e, por esta razão, não vejam motivos para se sentirem impostoras, uma vez que, para elas, não estão realizando nada de excepcional.

\section{CONSIDERAÇÕES FINAIS}

Com as crescentes conquistas pelas mulheres de espaços majoritariamente ocupado por homens, questões que tangem a esse processo, à forma como ele se deu e se dá, e os reflexos produzidos por essa inserção merecem atenção e estudo científico, visando a compreensão e ações eficazes, quando necessárias.

A Síndrome do Impostor começou a ser estudada por Clance e Imes (1978) e, desde então, muitos foram os trabalhos que corroboraram com a ideia de que a Síndrome não apenas afetava mulheres, gênero inicialmente estudado, como qualquer pessoa que estivesse alocada na condição de minoria.

O objetivo central dessa pesquisa foi verificar se a Síndrome do Impostor afeta as professoras de Ciências Contábeis e Administração da UFF, uma vez que elas estão inseridas em carreiras onde são minoria em seus departamentos, em detrimento da presença masculina, a qual é predominante nos dois cursos.

Oito professoras responderam o questionário de forma eletrônica, sendo 5 dessas do curso de Ciências Contábeis e 3 do curso de Administração. No entanto, contrariando alguns estudos anteriores, a maior parte do resultado demonstrou a presença de indicativo da Síndrome em nível baixo e moderado. Ainda que os resultados apresentados nessa pesquisa refutem pesquisas anteriores, a amostra analisada é diferenciada, pois se trata de professoras que, em geral, possuem um caminho mais longo a ser percorrido (graduação, mestrado, doutorado). Além disso, um concurso público é realizado para que elas possam ingressar na carreira docente, por isso, a percepção de sucesso dessas mulheres pode ser mais evidente nessa profissão do que nas demais pesquisadas.

Dessa maneira, verificou-se que há uma seara sobre o assunto que precisa ser atualizada e verificada em diversos meios, a fim de verificar se há um apontamento 
no sentido de diminuição da ocorrência da Síndrome, uma vez que muitas são as mudanças sociais às quais os indivíduos estão expostos.

Como indicativo de pesquisas futuras, sugere-se a repetição deste estudo com uma amostra maior, e, além disso, também se sugere a realização dessa pesquisa com professoras de universidades federais de campus centrais e maiores. Assim, é possível verificar se há influência da autopercepção de sucesso para o acometimento do fenômeno. 


\title{
Impostor Phenomenon and its relationship with teaching: a study with accounting and administration's teachers
}

\begin{abstract}
The purpose of this article was to check if the accounting and business female teachers from the University Federal Fluminense of the Volta Redonda/RJ are affected by Impostor Phenomenon, besides verifying the relation between presence of the syndrome and level of success. To get the results, 8 of whom answered test called the CIPS (Clance Impostor Phenomenon Scale), in which they could answer options between "not at all true" and "very true". After analysis the tests, it is possible to check a larger proportion of low and moderate level of phenomenon, the opposite of an international literature, which pointes to the sense that women, theoretically successful, would be more likely to developed the phenomenon in mainly male environments. In this way, it was concluded that the result of the changes that have occurred over time, since there is a very great temporal distance between the pioneer studies and the present article.
\end{abstract}

KEYWORDS: Gender. Women. Job market. Professional choices.

\section{El Síndrome del Impostor y su relación con la enseñanza: un estudio con los maestros de contabilidad y administración}

\begin{abstract}
RESUMEN
El objetivo de este estudio fue verificar si los profesores de Ciencias Contables de la Universidad Federal Fluminense están afectados por el Síndrome del Impostor y analizar la relación entre la presencia del síndrome y su nivel de éxito. Para obtener los resultados, 8 docentes respondieron el cuestionario, llamado escala CIPS. Tras el análisis de los datos, se concluyó que la mayoría de los docentes tenían un nivel de Síndrome indicativo bajo y moderado, en contra de la literatura internacional, que señalaba que las mujeres, teóricamente exitosas, tendrían más probabilidades de desarrollarse. Síndrome en ambientes mayoritariamente masculinos. Por lo tanto, se concluyó que el resultado encontrado puede ser el resultado de cambios en el tiempo, ya que existe una gran distancia temporal entre los estudios pioneros y el presente artículo.
\end{abstract}

PALABRAS CLAVE: Género. Mujer. Mercado de trabajo. Opciones profesionales. 


\section{REFERÊNCIAS}

BLAY, Eva Alterman; CONCEIÇÃO, Rosana R. A mulher como tema nas disciplinas da USP. Cadernos de Pesquisa, n. 76, p. 50-56, 2013.

BONIATTI, A. O.; VelHo, A. S.; PEREIRA, A.; PEREIRA, B. B.; OliVeIRA, S. M. A evolução da mulher no mercado contábil. Revista Gestão e Desenvolvimento em Contexto, v. 2, n. 1, p. 19-27, 2014.

BOURDIEU, Pierre. A dominação masculina. 2a edição. Rio de Janeiro: Bertrand Brasil, 2002.

BOURDIEU, Pierre. O poder simbólico. Rio de Janeiro: Bertrand Brasil, 1989.

BRASIL. Constituição da República Federativa do Brasil de 1988. Diário Oficial [da] República Federativa do Brasil, Brasília, DF. Disponível em: $<$ http://www.planalto.gov.br/ccivil_03/constituicao/constituicao.htm>. Acesso em 30 mai. 2018.

BRUSCHINI, Cristina; LOMBARDI, Maria Rosa. O trabalho da mulher brasileira nos primeiros anos da década de noventa. Anais..., p. 483-516, 1996.

BRUSCHINI, Cristina; PUPPIN, Andrea Brandão. Trabalho de mulheres executivas no Brasil no final do século XX. Cadernos de pesquisa, v. 34, n. 121, p. 105-138, 2004.

CAMPELLO, Bianca Coelho; DONATI, Luíza. A mulher contadora e seu espaço no mercado de trabalho. Pensar Contábil, v. 5, n. 16, 2015.

CAVALIERI, Claudia; FERNANDES, Reynaldo. Diferenciais de salários por gênero e cor: uma comparação entre as regiões metropolitanas brasileiras. Revista de Economia Política, v. 18, n. 1, 1998.

CLANCE, Pauline Rose. The Impostor Phenomenom: When Success Makes You Feel Like a Fake. Toronto: Bantam Books, 1985.

CLANCE, Pauline Rose; IMES, Suzanne Ament. The imposter phenomenon in high achieving women: Dynamics and therapeutic intervention. Psychotherapy: Theory, Research \& Practice, v. 15, n. 3, 1978.

CLANCE, Pauline Rose; O'TOOLE, Maureen Ann. The imposter phenomenon: An internal barrier to empowerment and achievement. Women\&Therapy, v. 6, n. 3, p. 51-64, 1988.

CONSELHO FEDERAL DE CONTABILIDADE (CFC). Profissionais Ativos nos Conselhos Regionais de Contabilidade agrupados por Gênero, 2017. Disponível em:<http://www3.cfc.org.br/spw/crcs/ConsultaPorRegiao.aspx?Tipo=0>. Acesso em 15 out. 2017.

COWMAN, Shaun E.; FERRARI, Joseph R. "Am I for real?" Predicting impostor tendencies from self-handicapping and affective components. Social Behavior and Personality: an international journal, v. 30, n. 2, p. 119-125, 2002. 
CRENSHAW, Kimberlé. Documento para o encontro de especialistas em aspectos da discriminação racial relativos ao gênero. Revista Estudos Feministas, v. 10, n. 1, p. 171-188, 2002.

FONSECA, J. J. S. Metodologia da pesquisa científica. Fortaleza: UEC, 2002.Apostila.

GIL, Antonio Carlos. Como Elaborar Projetos de Pesquisa. 4. Ed. São Paulo: Atlas, 2008.

HARVEY, Joan. The Impostor phenomenom and achievement: A failure to internalize success. Temple University, 1981.

HOLMES, Sarah W.; KERTAY, Les; ADAMSOM, Lauren B.; HOLLAND, C. L.; CLANCE, Pauline R. Measuring the impostor phenomenon: A comparison of Clance's IP Scale and Harvey's IP Scale. Journal of Personality Assessment, v. 60, n. 1, p. 48-59, 1993.

INSTITUTO NACIONAL DE ESTUDOS E PESQUISAS EDUCACIONAIS ANÍSIO TEIXEIRA (INEP). Censo da Educação Superior 2016 - principais resultados. Disponível em: <http://download.inep.gov.br/educacao_superior/censo_superior/documentos/ 2016/censo_supe rior_tabelas.pdf>. Acesso em: 18 out. 2017.

LEONE, Eugênia Troncoso. $O$ trabalho da mulher em regiões metropolitanas brasileiras. Trabalho, mercado e sociedade: o Brasil nos anos, v. 90, p. 199-230, 2003.

MATOS, Patricia Andréa Victorio Camargo de. Síndrome do impostor e autoeficácia de minorias sociais: alunos de contabilidade e administração. 2014. 91f.Dissertação (Mestrado em Controladoria e Contabilidade) - Departamento de Contabilidade e Atuária, Universidade de São Paulo, São Paulo, 2014.

MINAYO, Maria Cecília de Souza (Org.). Pesquisa social: teoria, método e criatividade. Petrópolis: Vozes, 2001.

OLIVEIRA, Nelio; OLIVEIRA, Rita de Cássia M.; DALFIOR, Simone. Gênero e novas perspectivas de trabalho: um estudo junto a mulheres gerentes de atendimento no Banco do Brasil. Anais...Encontro Nacional da Associação Nacional de PósGraduação e Pesquisa em Administração, 2000.

ROSKOWSKI, Jane C Royse. Imposter phenomenon and counseling self-efficacy: The impact of imposter feelings. 2010. Tese de Doutorado. Ball StateUniversity.

TAVARES, Sônia Prates Adonski. A evolução da mulher no contexto social e sua inserção no mundo do trabalho. 2012. 44f. Trabalho de Conclusão de Curso (Licenciatura Plena em História) - Departamento de História, Universidade Regional do Noroeste do Estado do Rio Grande do Sul - Unijuí, 2012.

WAJNMAN, Simone; RIOS-NETO, Eduardo. Quantas serão as mulheres: cenários para a atividade feminina. Trabalho e gênero: mudanças, permanências e desafios. São Paulo: Editora, v. 34, 2000. 
Recebido: 20/03/2019.

Aprovado: 20/06/2019.

DOI: $10.3895 /$ cgt.v12n40.9873

Como citar: ALVES, Mariana Azevedo; FERREIRA, Eduardo Cotrim; BONFIM, Mariana Pereira. A

Síndrome do Impostor e sua relação com a docência: um estudo com as professoras de ciências contábeis e administração. Cad. Gên. Tecnol., Curitiba, v. 12, n. 40, p. 278-294, jul./dez. 2019. Disponível em:

https://periodicos.utfpr.edu.br/cgt. Acesso em: XXX.

Correspondência:

Mariana Azevedo Alves

Rua Desembargador Ellis Hermydio Figueira, 783 - sala 301 - Bloco A, Volta Redonda - Rio de Janeiro,

Brasil

Direito autoral: Este artigo está licenciado sob os termos da Licença Creative Commons-Atribuição 4.0 Internacional.

\section{(c) (1)}

